\title{
Hydroxyethyl starch is associated with early postoperative delirium in patients undergoing esophagectomy
}

\author{
Dae Myung Jung, MD, Hyun Joo Ahn, MD, PhD, Mikyung Yang, MD, PhD, Jie Ae Kim, MD, PhD, \\ Duck Kyung Kim, MD, PhD, Sangmin Maria Lee, MD, PhD, and Joo Hyun Park, MD
}

\section{ABSTRACT}

Objective: Postoperative delirium is associated with longer hospital stay and increased morbidities. Patients undergoing esophagectomy have a high chance of developing postoperative delirium because of their advanced age, comorbidities, and intensive care unit care. In this study, we investigated the risk factors of early postoperative delirium in patients undergoing esophagectomy, focusing on perioperative fluid type to test the hypothesis that colloids with high oncotic pressure and anti-inflammatory action would decrease the incidence of postoperative delirium compared with crystalloids.

Methods: All patients who underwent esophagectomy from 2010 to 2015 in a tertiary care center were reviewed in this retrospective study $(\mathrm{n}=1041)$. Patients who showed positive Confusion Assessment Method or received haloperidol within 4 days postoperatively were enrolled as those with postoperative delirium $(+)$. Multivariable logistic regression was performed to identify risk factors for postoperative delirium. Incidence of postoperative delirium was compared among crystalloids, hydroxyethyl starch, and albumin groups after propensity score matching.

Results: The incidence of delirium within postoperative 4 days was $22.7 \%$. Infusion of hydroxyethyl starch was an independent risk factor (odds ratio [OR], 1.53; $95 \%$ confidence interval $[\mathrm{CI}], 1.09-2.14 ; P=.0151)$. Other risk factors were age (OR, 1.04; 1.02-1.06, per year; $P=.0002)$, preoperative cerebrovascular disease (OR, 2.18; 1.15-4.12; $P=.0170)$, pulmonary dysfunction (OR, 1.85; 1.33-2.58; $P=.0003)$, and transfusion $(\mathrm{OR}, 1.76 ; 1.22-2.53 ; P=.0023)$. Propensity score matching analysis confirmed that administration of hydroxyethyl starch, but not albumin, is related to postoperative delirium.

Conclusions: Old age, preoperative cerebrovascular disease, pulmonary dysfunction, transfusion, and hydroxyethyl starch administration were related to early postoperative delirium. If colloid must be administered, albumin is preferred to hydroxyethyl starch. (J Thorac Cardiovasc Surg 2018;155:1333-43)

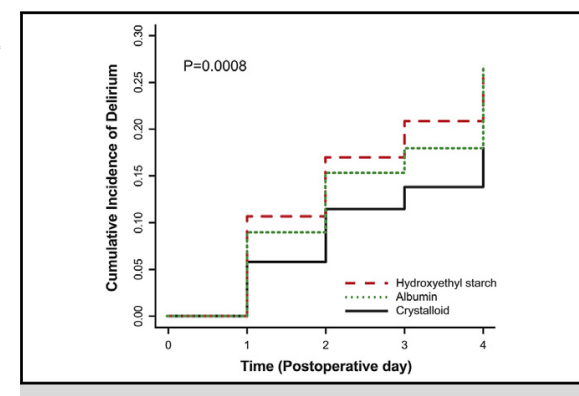

Cumulative incidence of delirium according to fluid types.

\section{Central Message}

Administration of hydroxyethyl starch is associated with an increased risk of early postoperative delirium in esophagectomy.

\section{Perspective}

Risk factors for early postoperative delirium are not elucidated enough in patients undergoing esophagectomy. In the current study, old age, preoperative cerebrovascular disease, pulmonary dysfunction, transfusion, and hydroxyethyl starch administration were related to delirium occurring within postoperative 4 days. If colloid must be administered, albumin is preferred to hydroxyethyl starch.

See Editorial Commentary page 1344.

See Editorial page 1331.
Postoperative delirium is a serious problem, with an incidence of $8 \%$ to $54 \%$ among elderly patients undergoing gastrointestinal surgery. ${ }^{1}$ Postoperative delirium not only is associated with longer hospital stay and increased

\footnotetext{
From the Department of Anesthesiology and Pain Medicine, Samsung Medical Center, Sungkyunkwan University School of Medicine, Seoul, Korea.

Date of Institutional Review Board approval: January 27, 2016; number of Institutional Review Board approval: 2016-01-089-001.

Received for publication July 25, 2016; revisions received Aug 22, 2017; accepted for publication Oct 23, 2017; available ahead of print Dec 6, 2017.

Address for reprints: Hyun Joo Ahn, MD, PhD, Department of Anesthesiology and Pain Medicine, Samsung Medical Center, 50, Ilwon-Dong, Kangnam-Gu, Seoul, Korea 06351 (E-mail: hyunjooahn@skku.edu). $0022-5223 / \$ 36.00$

Copyright (c) 2017 by The American Association for Thoracic Surgery https://doi.org/10.1016/j.jtcvs.2017.10.077
}

hospital costs but also increases the rate of complications and mortality. ${ }^{2-4}$

Patients undergoing surgery for esophageal cancer usually have a number of risk factors related to postoperative delirium, including advanced age, male gender, high rate of comorbidities, dehydration, metabolic derangement, pain, and intensive care unit (ICU) care. ${ }^{1,2,5}$ However, few

- Scanning this $\mathrm{QR}$ code will take you to a supplemental video for this article. 


$$
\begin{aligned}
& \text { Abbreviations and Acronyms } \\
& \text { ASA }=\text { American Society of Anesthesiologists } \\
& \text { BMI }=\text { body mass index } \\
& \text { CAM }=\text { Confusion Assessment Method } \\
& \text { CI }=\text { confidence interval } \\
& \text { ICU }=\text { intensive care unit } \\
& \text { OR }=\text { odds ratio } \\
& \text { POD }=\text { postoperative day } \\
& \text { PS }=\text { propensity score } \\
& \text { PSM }=\text { propensity score matching }
\end{aligned}
$$

studies have addressed postoperative delirium after esophagectomy.

Avoiding fluid overload is important in esophagectomy to prevent postoperative acute lung injury. ${ }^{6,7}$ However, maintenance of sufficient tissue perfusion is equally important for optimal outcomes. ${ }^{8}$ These considerations typically lead to the use of colloids to compensate for perioperative losses from the patient's circulation. ${ }^{9}$ A previous study reported that appropriate use of colloids may be beneficial during esophagectomy. ${ }^{6}$ However, there are many debates regarding the use of synthetic colloids because of reports of increased renal injury, coagulopathy, and mortality, especially in patients with sepsis and patients in the ICU. ${ }^{10-12}$

It is not known which types of fluid are most beneficial with respect to early postoperative delirium that is not originated from surgical complications or deterioration of the patient's condition. An unbalanced neuroinflammatory response is suggested as a cause of delirium. ${ }^{13,14}$ Colloids are reported to possess anti-inflammatory action. ${ }^{15}$ In addition, a colloid with high oncotic pressure was shown to be more effective for reducing brain edema than crystalloids. ${ }^{16,17}$

Therefore, in this retrospective study we first investigated the incidence and risk factors for postoperative delirium within 4 days after esophagectomy. Next, we focused on the association between 3 types of fluid (crystalloids, hydroxyethyl starch, and albumin) and postoperative delirium. We hypothesized that colloids are related to a reduced incidence of early postoperative delirium compared with crystalloids in esophagectomy.

\section{MATERIALS AND METHODS \\ Patient Selection and Variables}

Our institutional review board approved this retrospective cohort study (Institutional Review Board file number: 2016-01-089-001). Electronic medical records were reviewed for all patients who had been diagnosed with esophageal cancer and had undergone esophagectomy between April 2010 and February 2015 at a tertiary care university hospital. This research used patients' data, which had the written consent from the patient to provide his or her medical records for the comprehensive research purposes.
Various preoperative, intraoperative, and postoperative variables were investigated for association with occurrence of postoperative delirium within 4 days. Data were collected from electronic medical records and records of the thoracic surgery database.

Preoperative data included age, gender, body mass index (BMI), American Society of Anesthesiologists (ASA) physical status classification, academic background (high school graduate or less), heavy drinking (consuming $\geq 15$ drinks per week for men or $\geq 8$ drinks per week for women as defined by the Centers for Disease Control and Prevention), smoking (a current smoker or someone who had stopped smoking $<1$ month previously), diabetes mellitus, hypertension, cardiac disease (history of heart failure, angina, myocardial infarction, percutaneous coronary intervention, and coronary artery bypass graft), cerebrovascular disease (history of cerebral infarction, cerebral hemorrhage, and dementia/ Parkinson disease/Alzheimer disease), liver disease (history of liver cirrhosis and hepatitis), pulmonary disease (chronic obstructive pulmonary disease, bronchiectasis, asthma, interstitial lung disease), cancer stage and neoadjuvant therapy, forced expiratory volume in 1 second, hemoglobin, serum albumin, and creatinine.

Intraoperative data included operative time and type of surgery (operation names, minimally invasive esophagectomy).

Data on pain control methods, transfusion (operation day), use of vasopressors/inotropes (operation day, continuous infusion only), fluid amount (until postoperative day [POD]2), use of opioids and sedatives (until POD4), postoperative complications (until POD4) and mortality (until discharge), and ICU and hospital stay were collected. Cumulative opioid use until POD4 was calculated by converting all opioids into morphine equivalent based on our institutional guidelines (morphine $10 \mathrm{mg}=$ hydromorphone $1.5 \mathrm{mg}=$ pethidine $75 \mathrm{mg}=$ fentanyl $100 \mu \mathrm{g}$ ). Cumulative sedative use was transformed to the dose of midazolam.

\section{Perioperative Management}

All cases were managed under the esophagectomy critical pathway of our institution. All patients scheduled for esophagectomy fasted after breakfast on the day before surgery. Fasting hours varied in the range of 19 to 24 hours among patients depending on the time of surgery. Patients received intravenous fluid during the fasting hours (dextrose water $80 \mathrm{~mL} / \mathrm{h}$ and lactated Ringer's solution $40 \mathrm{~mL} / \mathrm{h}$ ). No premedication was given before the induction of anesthesia. For induction of anesthesia, a 1.5 to $2.5 \mathrm{mg} / \mathrm{kg}$ propofol bolus with remifentanil continuous infusion was used. Intubation was performed using a left-sided double-lumen tube (Broncho-Cath; Mallinckrodt Laboratories, Athlone, Ireland), and its position was confirmed by fiberoptic bronchoscopy. During esophagectomy, anesthesia was maintained with a combination of volatile anesthetic agent and continuous infusion of muscle relaxant and remifentanil. Mechanical ventilation during 1-lung ventilation was maintained with a tidal volume of 5 to $7 \mathrm{~mL} / \mathrm{kg}$ of predicted body weight and a ventilation rate of 10 to $15 / \mathrm{min}$ to maintain end-tidal $\mathrm{CO}_{2}$ in the appropriate range. Unless it was contraindicated, 5 to $7 \mathrm{cmH}_{2} \mathrm{O}$ of positive endexpiratory pressure was usually applied.

Zero fluid balance was the intraoperative target for esophagectomy. Maintenance fluid was administered at a rate of 3 to $5 \mathrm{~mL} / \mathrm{kg} / \mathrm{h}$ or less until the end of surgery and 2 to $3 \mathrm{~mL} / \mathrm{kg} / \mathrm{h}$ after the operation. During operation, low blood pressure without significant blood loss or intravascular volume deficiency was managed by administration of vasopressors/inotropes. If no response or volume deficiency was suspected, $6 \%$ hydroxyethyl starch (Hextend [Biotime, Alameda, Calif], Volulyte [Kabi, Bad Homburg, Germany]), 5\% human albumin (Green Cross, Yongin, Gyeonggi), or additional crystalloid (plasma solution, CJ, Seoul, Korea) was given to the patient at the discretion of the attending anesthesiologist. After operation, the ICU physician administered fluid according to the patient's vital signs. Hypotension was first treated with fluid loading, and if there was no response, epidural analgesia was stopped and vasoactive drugs were added.

Pain-control methods were intravenous patient-controlled analgesia or epidural patient-controlled analgesia. Thoracic epidural was performed 
TABLE 1. Demographic and operative characteristics between delirium (-) and delirium (+) patients: Incidence of delirium was $22.7 \%$ in total population

\begin{tabular}{|c|c|c|c|}
\hline Variables & $\begin{array}{c}\text { Delirium (-) } \\
\mathbf{N}=\mathbf{7 5 8}\end{array}$ & $\begin{array}{c}\text { Delirium (+) } \\
\mathbf{N}=\mathbf{2 2 2}\end{array}$ & $P$ value \\
\hline \multicolumn{4}{|l|}{ Patient factors } \\
\hline Age, y & $63 \pm 9$ & $65 \pm 8$ & $<.001$ \\
\hline Sex & & & .10 \\
\hline Male $(\mathrm{n}=895), \mathrm{n}$ & $686(77)$ & $209(23)$ & \\
\hline Female $(\mathrm{n}=85), \mathrm{n}$ & $72(85)$ & $13(15)$ & \\
\hline BMI, $\mathrm{kg} /(\mathrm{m})^{2}$ & $22 \pm 4$ & $23 \pm 3$ & .34 \\
\hline ASA class, $\mathrm{n}$ & & & .046 \\
\hline II $(\mathrm{n}=718)$ & $559(78)$ & $159(22)$ & \\
\hline $\mathrm{III}(\mathrm{n}=52)$ & $33(63)$ & $19(37)$ & \\
\hline Lower education $(\mathrm{n}=744), \mathrm{n}$ & $566(76)$ & $178(24)$ & .11 \\
\hline Heavy drinking $(\mathrm{n}=277), \mathrm{n}$ & $205(74)$ & $72(26)$ & .13 \\
\hline Current smoking $(\mathrm{n}=212), \mathrm{n}$ & $150(71)$ & $62(29)$ & .053 \\
\hline Diabetes mellitus $(\mathrm{n}=147), \mathrm{n}$ & $111(76)$ & $36(24)$ & .59 \\
\hline Hypertension $(\mathrm{n}=361), \mathrm{n}$ & $278(77)$ & $83(23)$ & .95 \\
\hline Lung disease $(n=42), n$ & $32(76)$ & $10(24)$ & .85 \\
\hline Cardiac disease $(n=44), n$ & $35(80)$ & $9(20)$ & .85 \\
\hline Cerebrovascular disease $(n=49), n$ & $30(61)$ & $19(39)$ & .008 \\
\hline Liver disease $(\mathrm{n}=46), \mathrm{n}$ & $30(65)$ & $16(35)$ & .06 \\
\hline Neoadjuvant treatment $(n=156), n$ & $123(79)$ & $33(21)$ & .58 \\
\hline Clinical tumor stage, $\mathrm{n}$ & & & .13 \\
\hline $\mathrm{I}(\mathrm{n}=291)$ & $229(79)$ & $62(21)$ & \\
\hline $\mathrm{II}(\mathrm{n}=216)$ & $155(72)$ & $61(28)$ & \\
\hline III $(\mathrm{n}=197)$ & $155(79)$ & $42(21)$ & \\
\hline \multicolumn{4}{|l|}{ Laboratory studies } \\
\hline FEV1, \% & $73 \pm 10$ & $70 \pm 10$ & .002 \\
\hline Preoperative creatinine, $\mathrm{mg} / \mathrm{dL}$ & $0.86(0.75-0.97)$ & $0.91(0.80-1.00)$ & .002 \\
\hline Preoperative albumin, g/dL & $4.3 \pm 0.4$ & $4.3 \pm 0.4$ & .32 \\
\hline Preoperative $\mathrm{Hgb}, \mathrm{g} / \mathrm{dL}$ & $13.5 \pm 1.8$ & $13.5 \pm 1.9$ & .99 \\
\hline \multicolumn{4}{|l|}{ Perioperative variables } \\
\hline Operative time, min & $296 \pm 91$ & $303 \pm 90$ & .36 \\
\hline Vasopressor $(\mathrm{n}=564), \mathrm{n}$ & $426(76)$ & $138(24)$ & .11 \\
\hline Inotrope $(\mathrm{n}=232), \mathrm{n}$ & $177(76)$ & $55(24)$ & .66 \\
\hline Transfusion $(\mathrm{n}=195), \mathrm{n}$ & $133(68)$ & $62(32)$ & .001 \\
\hline Fluid, $\mathrm{n}$ & & & .019 \\
\hline Crystalloid $(\mathrm{n}=393)$ & $322(82)$ & $71(18)$ & \\
\hline Hydroxyethyl starch $(\mathrm{n}=509)$ & $379(74)$ & $130(26)$ & \\
\hline Albumin $(\mathrm{n}=78)$ & $57(73)$ & $21(27)$ & \\
\hline Minimally invasive surgery $(n=133), n$ & $112(84)$ & $21(16)$ & .06 \\
\hline Operation name, $\mathrm{n}$ & & & .004 \\
\hline Ivor-Lewis $(\mathrm{n}=541)$ & $398(74)$ & $143(26)$ & \\
\hline 3-field $(n=167)$ & $126(75)$ & $41(25)$ & \\
\hline 3-hole $(\mathrm{n}=115)$ & $99(86)$ & $16(14)$ & \\
\hline Esophagocolonogastrostomy $(\mathrm{n}=53)$ & $44(83)$ & $9(17)$ & \\
\hline Transhiatal $(\mathrm{n}=33)$ & $29(88)$ & $4(12)$ & \\
\hline Total gastrectomy $(\mathrm{n}=31)$ & $29(94)$ & $2(6)$ & \\
\hline Epidural $(\mathrm{n}=355), \mathrm{n}$ & $269(76)$ & $86(24)$ & .38 \\
\hline \multicolumn{4}{|l|}{ Numeric pain score } \\
\hline POD0 & $2.8 \pm 2.4$ & $2.9 \pm 2.4$ & .71 \\
\hline POD1 & $5.7 \pm 2.1$ & $6.0 \pm 2.0$ & .08 \\
\hline POD2 & $5.3 \pm 2.3$ & $5.0 \pm 2.3$ & .12 \\
\hline
\end{tabular}

Values are mean \pm standard deviation, median (interquartile), or number (\%). Lower education, high school graduate or less; neoadjuvant, chemotherapy alone, and chemoradiation; tumor stage, American Joint Committee on Cancer clinical tumor staging system (cTMN7, cStage 7); current smoking, current smoker or stop smoking within 1 month before operation; pulmonary dysfunction, lung disease + smoking + FEV1 $<60 \%$; vasopressors, phenylephrine, or norepinephrine; Inotropes, dopamine, or dobutamine; 3 -field, 3-field lymph node dissection, and esophagogastrostomy; esophagocolonogastrostomy, esophagocolonogastrostomy, or esophagocolonojejunostomy; transhiatal, transhiatal esophagectomy, and esophagogastrostomy; total gastrectomy, total gastrectomy, and esophagojejunostomy; numeric pain score, $0=$ no pain, $10=$ worst pain imaginable. $B M I$, Body mass index; ASA, American Society of Anesthesiologists; FEVI, forced expiratory volume in 1 second; Hgb, hemoglobin; POD, postoperative day. 
TABLE 2. Risk factors of postoperative delirium

\begin{tabular}{|c|c|c|c|c|c|c|}
\hline \multirow[b]{2}{*}{ Risk factors } & \multicolumn{3}{|c|}{ Univariable analysis } & \multicolumn{3}{|c|}{ Multivariable analysis } \\
\hline & $\overline{\text { OR }}$ & $95 \% \mathrm{CI}$ & $P$ & OR & $95 \% \mathrm{CI}$ & $P$ \\
\hline Age, per year & 1.03 & $1.01-1.05$ & .001 & 1.04 & $1.02-1.06$ & $<.001$ \\
\hline Transfusion & 1.80 & $1.27-2.56$ & .001 & 1.76 & $1.22-2.53$ & .002 \\
\hline Cerebrovascular disease & 2.14 & $1.15-3.99$ & .017 & 2.18 & $1.15-4.12$ & .017 \\
\hline Pulmonary dysfunction & 1.73 & $1.26-2.39$ & .001 & 1.85 & $1.33-2.58$ & $<.001$ \\
\hline \multicolumn{7}{|l|}{ Fluids } \\
\hline Hydroxyethyl starch & 1.64 & $1.18-2.28$ & .003 & 1.53 & $1.09-2.14$ & .015 \\
\hline Albumin & 1.69 & $0.96-2.97$ & .07 & & & \\
\hline Male & 1.69 & $0.92-3.11$ & .09 & & & \\
\hline ASA class III & 2.40 & $1.23-4.67$ & .010 & & & \\
\hline Heavy drinking & 1.25 & $0.90-1.74$ & .19 & & & \\
\hline Lower education & 1.35 & $0.93-1.96$ & .11 & & & \\
\hline Liver disease & 2.02 & $1.05-3.88$ & .040 & & & \\
\hline Preoperative creatinine, $\mathrm{mg} / \mathrm{dL}$ & 1.36 & $0.88-2.11$ & .16 & & & \\
\hline Vasopressor & 1.34 & $0.98-1.83$ & .07 & & & \\
\hline Minimally invasive surgery & 0.60 & $0.37-0.98$ & .042 & & & \\
\hline Fluid balance & 1.00 & $1.00-1.00$ & .19 & & & \\
\hline
\end{tabular}

All variables are preoperative or operative day variables. Variables with $P<.2$ in univariable analysis were entered into multivariable analysis. Pulmonary dysfunction, current smoker + lung disease + FEV1 $<60 \%$; education, high school graduate or less; vasopressors were phenylephrine or norepinephrine. OR, Odds ratio; $C I$, confidence interval; $A S A$, American Society of Anesthesiologists.

before operation at the institutional pain service center. The epidural solution was a mixture of ropivacaine $(0.15 \%)$ plus hydromorphone $(8 \mu \mathrm{g} / \mathrm{mL})$ and infused at a basal rate of $5 \mathrm{~mL} / \mathrm{h}$ with $3 \mathrm{~mL}$ of bolus and a 15 -minute lockout interval. Epidural doses were started near the end of operation.

\section{Surgical Procedures and Postoperative Management}

All patients who were scheduled for esophagectomy underwent routine preoperative laboratory tests and preoperative staging workup using computed tomography and positron emission tomography. Types of surgery were Ivor-Lewis operation, 3-field lymph node dissection and esophagogastrostomy, 3-hole operation, esophagocolonogastrostomy, esophagocolonojejunostomy, transhiatal esophagectomy and esophagogastrostomy, total gastrectomy, and esophagojejunostomy. In the Ivor-Lewis operation, midline laparotomy for abdominal procedure was performed first, followed by right posterolateral thoracotomy for thoracic esophagectomy. In 3-hole and 3-field lymph node dissection, right posterolateral thoracotomy for esophagectomy and dissection of mediastinal lymph nodes were followed by midline laparotomy and cervical low incision.

After the surgery, patients were transferred to the ICU with an endotracheal tube and placed on mechanical ventilation until the next morning. Patients usually received pressure-controlled ventilation with $6 \mathrm{~mL} / \mathrm{kg}$ tidal volume, $5 \mathrm{cmH}_{2} \mathrm{O}$ positive end-expiratory pressure, and fraction of inspired oxygen 0.3 to 0.4 . Remifentanil was continuously infused to provide analgesia and sedation during ventilator care. On POD1 morning, an ICU physician carried out staged extubation after providing lung toileting and confirming adequate recovery of lung function. Patients were encouraged to ambulate at the bedside. The ICU physician allowed transfer to the general ward on POD2 when the patient had accomplished walking ambulation without any problems.

\section{Delirium Assessment}

Postoperative delirium was defined when the Confusion Assessment Method (CAM) was positive during the ICU stay or when haloperidol was administered in the ward within 4 days after surgery (CAM data were not available in ward). The CAM has 4 features $^{18}$ : (1) an acute onset of mental status changes or a fluctuating course; (2) inattention; (3) disorganized thinking; and (4) an altered level of consciousness. The patient is diagnosed as delirious (ie, CAM positive) if he or she has both features 1 and 2 and either feature 3 or 4 . Trained ICU nurses assessed delirium every hour until ICU discharge. Delirium was assessed for the first 4 days postoperatively in an effort to exclude delirium originated from surgical complications, such as pneumonia, acute lung injury, sepsis, or conduit leak, which often occur after postoperative 3 or 4 days. ${ }^{19}$

\section{Statistical Analysis}

Categoric variables were reported as the number and percentage. Continuous variables were expressed as the mean and standard deviation or median and interquartile ranges. Comparison among fluid groups was conducted with chi-square test or Fisher exact test for categoric variables and with 1-way analysis of variance, Kruskal-Wallis test, $t$ test, or MannWhitney test for continuous variables. First, we investigated predictors for postoperative delirium using multivariable logistic regression model with stepwise variable selection (entry rule $=0.2$, stay rule $=0.1$ ). The final multivariable logistic regression model was internally validated via $10-$ fold cross-validation as well as resampling with 1000 bootstrap datasets. The C-statistic was used as a prediction performance index. Second, a propensity score matching (PSM) analysis was used to compare the incidence of postoperative delirium among studied fluids. ${ }^{20}$ Matched variables were sex, age, BMI, education, heavy drinking, diabetes mellitus, hypertension, pulmonary dysfunction, cerebrovascular disease, liver disease, operation duration, minimally invasive surgery, preoperative creatinine, preoperative albumin, preoperative hemoglobin, epidural analgesia, operation day inotropes, operation day vasopressors, operation day transfusion, and operation day fluid balance. PSM was conducted in a pairwise manner: matching each of groups receiving hydroxyethyl starch or albumin with a reference group receiving crystalloid. We calculated the propensity score by nonparsimonious logistic regression in which the 


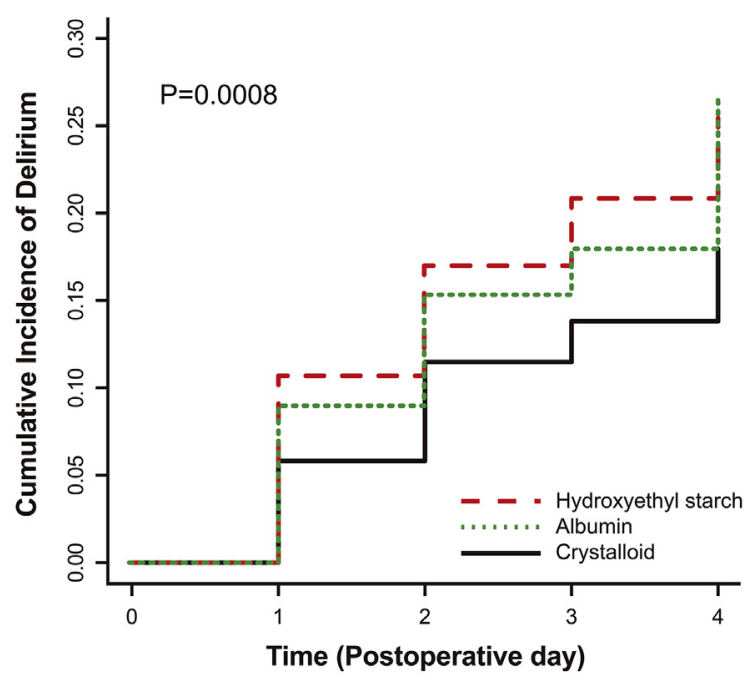

Number at risk $(95 \% \mathrm{Cl})$

\begin{tabular}{|l|c|c|c|c|}
\hline Hydroxyethyl starch & $\begin{array}{c}471 \\
(0.13-0.08)\end{array}$ & $\begin{array}{c}421 \\
(0.20-0.14)\end{array}$ & $\begin{array}{c}391 \\
(0.24-0.17)\end{array}$ & $\begin{array}{c}373 \\
(0.30-0.22)\end{array}$ \\
\hline Albumin & $\begin{array}{c}78 \\
(0.15-0.02)\end{array}$ & $\begin{array}{c}71 \\
(0.23-0.07)\end{array}$ & $\begin{array}{c}66 \\
(0.26-0.09)\end{array}$ & $\begin{array}{c}64 \\
(0.36-0.16)\end{array}$ \\
\hline Crystalloid & 391 & 368 & 346 & 337 \\
& $(0.08-0.04)$ & $(0.15-0.08)$ & $(0.17-0.10)$ & $(0.22-0.14)$ \\
\hline
\end{tabular}

FIGURE 1. Cumulative incidence of delirium. Incidence of postoperative delirium differed among the 3 groups (logistic regression, $P=.0008$ ). The $\mathrm{H}$ group has higher incidence of postoperative delirium than the $\mathrm{C}$ group (between $\mathrm{C}$ and $\mathrm{H}$ groups, $P=.0381$; between $\mathrm{C}$ and $\mathrm{A}$ groups, $P=.61$, between $\mathrm{H}$ and A groups, $P=1.0$, Bonferroni correction done). $C I$, Confidence interval.

outcome was delirium and the covariates were basic characteristics and preoperative variables. The caliper was set as $25 \%$ of standard deviation of the logit of the propensity scores. Then, $1: \mathrm{k}$ matching at variable ratio of up to 1:2 was used for both hydroxyethyl starch and crystalloid groups, and albumin and crystalloid groups. ${ }^{21}$ To evaluate PSM results, we assessed the balance in baseline covariates through the standardized mean difference $(<0.1)$. All statistical analyses with the matched data after PSM were performed with the robust sandwich estimation by considering the structure of each matching pair as a cluster. Incidence rate of postoperative delirium was compared between the matched groups on the basis of a weighted logistic regression with cluster effects. All statistical analyses were conducted using SAS version 9.4 (SAS Institute, Inc, Cary, NC) and "MatchIt" package in R 3.3.1 (Vienna, Austria; http://www. R-project.org/).

\section{RESULTS}

A total of 1041 cases of esophagectomy performed between April 2010 and February 2015 were reviewed. Of these, 61 patients who had received $6 \%$ hydroxyethyl starch and albumin simultaneously were excluded. The remaining 980 patients were entered into analysis.

The incidence of postoperative delirium was $22.7 \%$. Delirium was mostly developed on POD1 and 2 (POD1: $36 \%$, POD2 29\%, POD3 13\%, POD4 22\%). The patient characteristics between delirium $(-)$ and $(+)$ are summarized in the Table 1. Patients with delirium $(+)$ were more elderly and had higher ASA classification, preoperative cerebrovascular disease, lower forced expiratory volume in 1 second, and higher serum creatinine. Patients with delirium $(+)$ received transfusion more often during the operation day. Type of fluids on the operation day was different between delirium $(-)$ and $(+)$.

Identified risk factors of postoperative delirium by multivariable logistic regression were age (odds ratio [OR], 1.04; $95 \%$ confidence interval [CI], 1.02-1.06, per year; $P=.0002)$, preoperative cerebrovascular disease (OR, $2.18 ; 95 \% \mathrm{CI}, 1.15-4.12 ; P=.0170)$, preoperative pulmonary dysfunction (OR, 1.85; 95\% CI, 1.33-2.58; $P=.0003$ ), transfusion (OR, 1.76; 95\% CI, 1.22-2.53; $P=.0023)$, and hydroxyethyl starch administration (OR, 1.53 ; $95 \% \mathrm{CI}, 1.09-2.14 ; P=.0151)$ on operation day (Table 2). The area under the receiver operating characteristics curve of the final multivariable logistic regression model was 0.66 . This was internally validated via 10 -fold cross-validation and resampling with 1000 bootstrap datasets (C-statistics: original set $=0.66,10$ fold crossvalidation set $=0.64$, resampling set $=0.63$ ). $P$ value of Hosmer and Lemeshow goodness-of-fit was 0.53.

Because fluid type was an independent risk factor for delirium from multivariable analysis and the only modifiable one, we focused on the effect of fluids. Patients were divided into 3 groups according to administered fluids: (1) crystalloids alone (C group, $n=393$ ), (2) $6 \%$ hydroxyethyl starch ( $\mathrm{H}$ group, $\mathrm{n}=509$ ), and (3) albumin (A group, $\mathrm{n}=78$ ). Incidence of postoperative delirium differed among the 3 groups (71/393 [18\%], 130/509 [28\%], 21/ $78[27 \%]$, in the $\mathrm{C}, \mathrm{H}$, and $\mathrm{A}$ groups, respectively, $P=.0008)$. The $\mathrm{H}$ group had a higher incidence of postoperative delirium than the $\mathrm{C}$ group (between $\mathrm{C}$ and $\mathrm{H}$ groups, $P=.0381$; between $\mathrm{C}$ and A groups, $P=.61$, between $\mathrm{H}$ and A groups, $P=1.0$, Bonferroni correction done). Occurrence of delirium in the 3 groups is presented as a cumulative incidence in Figure 1.

Fluid balance (input [fluid + transfusion] - output [urine + chest bottle]) until POD2 was not different among the $\mathrm{C}, \mathrm{H}$, and A groups (POD 1: $1305 \pm 609 \mathrm{~mL}$, $1398 \pm 649 \mathrm{~mL}, 1271 \pm 694, P=.051$; POD2: $493 \pm 512 \mathrm{~mL}, 524 \pm 550 \mathrm{~mL}, 570 \pm 508 \mathrm{~mL}, P=.44)$.

However, fluid balance on operative day (input [fluid + transfusion] - output [bleeding + urine + chest bottle]) was different among the groups (median [interquartile]: 250 [0-620], 499 [120-894], 445 [189-901], $P<.0001$, $\mathrm{C}, \mathrm{H}$, and A groups, respectively, $P<.05$ between $\mathrm{C}$ and $\mathrm{H}$, $\mathrm{C}$, and $\mathrm{A}$ groups, no difference between $\mathrm{H}$ and $\mathrm{A}$ groups).

In addition, several variables showed more than $20 \%$ of standardized mean difference; (pulmonary dysfunction, heavy drinking, preoperative albumin, preoperative hemoglobin, operation day vasopressor, minimally invasive surgery, thoracic epidural analgesia). Therefore, PSM analysis was conducted. The matched variables were age, sex, BMI, ASA classification, education, heavy drinking, 
TABLE 3. Propensity score matching between crystalloid alone group and hydroxyethyl starch group

\begin{tabular}{|c|c|c|c|c|c|c|}
\hline \multirow[b]{2}{*}{ Risk factors } & \multicolumn{3}{|c|}{ Before matching } & \multicolumn{3}{|c|}{ After matching } \\
\hline & $\overline{C(n=391)}$ & $H(n=471)$ & SMD & $\bar{C}(\mathrm{n}=\mathbf{3 3 4})$ & $H(n=439)$ & SMD \\
\hline Male, $\mathrm{n}$ & $348(89)$ & $435(92)$ & 0.116 & $300(90)$ & $400(91)$ & 0.041 \\
\hline Age, $y$ & $63(9)$ & $63(8)$ & 0.011 & $63(10)$ & $63(8)$ & 0.015 \\
\hline BMI, $\mathrm{kg} /(\mathrm{m})^{2}$ & $23(3)$ & $23(3)$ & 0.066 & $22(3)$ & $23(3)$ & 0.038 \\
\hline ASA class III, $\mathrm{n}$ & $21(5)$ & $23(5)$ & 0.022 & $19(6)$ & $22(5)$ & 0.027 \\
\hline Lower education, $\mathrm{n}$ & $281(72)$ & 367 (78) & 0.140 & $249(75)$ & $337(77)$ & 0.052 \\
\hline Heavy drinking, $\mathrm{n}$ & $105(27)$ & $130(28)$ & 0.017 & $91(27)$ & $118(27)$ & 0.010 \\
\hline Diabetes mellitus, $\mathrm{n}$ & $59(15)$ & $68(14)$ & 0.018 & $51(15)$ & $64(15)$ & 0.017 \\
\hline Hypertension, $\mathrm{n}$ & $156(40)$ & $179(38)$ & 0.039 & $133(40)$ & $170(39)$ & 0.021 \\
\hline Pulmonary dysfunction, $\mathrm{n}$ & $94(24)$ & $163(34)$ & 0.234 & $89(27)$ & $124(28)$ & 0.037 \\
\hline Cardiac disease, $\mathrm{n}$ & $23(6)$ & $17(4)$ & 0.107 & $18(5)$ & $14(3)$ & 0.111 \\
\hline Cerebral disease, $\mathrm{n}$ & $18(5)$ & $24(5)$ & 0.023 & $16(5)$ & $23(5)$ & 0.021 \\
\hline Liver disease, $\mathrm{n}$ & $14(4)$ & $22(5)$ & 0.055 & $13(4)$ & $18(4)$ & 0.015 \\
\hline $\begin{array}{l}\text { Preoperative creatinine, } \\
\mathrm{mg} / \mathrm{dL}\end{array}$ & $0.9(0.3)$ & $0.9(0.4)$ & 0.071 & $0.9(0.3)$ & $0.9(0.2)$ & 0.024 \\
\hline Preoperative albumin, $g / d L$ & $4.3(0.4)$ & $4.3(0.4)$ & 0.017 & $4.3(0.4)$ & $4.3(0.4)$ & 0.018 \\
\hline Preoperative $\mathrm{Hgb}, \mathrm{g} / \mathrm{dL}$ & $14(2)$ & $14(2)$ & 0.075 & $13(2)$ & $14(2)$ & 0.010 \\
\hline Operative time, $\min$ & $298(98)$ & $293(78)$ & 0.052 & $296(101)$ & $293(77)$ & 0.038 \\
\hline Inotrope, $\mathrm{n}$ & $89(23)$ & $110(24)$ & 0.014 & $76(23)$ & $99(23)$ & 0.004 \\
\hline Vasopressor, $\mathrm{n}$ & $196(50)$ & $286(61)$ & 0.214 & $180(54)$ & $241(55)$ & 0.021 \\
\hline Transfusion, $\mathrm{n}$ & $15(4)$ & $31(7)$ & 0.124 & $59(18)$ & $83(19)$ & 0.031 \\
\hline Fluid balance, $\mathrm{mL}$ & $323(470)$ & $534(535)$ & 0.419 & $369(480)$ & $411(485)$ & 0.086 \\
\hline Minimally invasive surgery, $n$ & $84(22)$ & $42(9)$ & 0.355 & $51(15)$ & $49(11)$ & 0.119 \\
\hline Epidural, $\mathrm{n}$ & $134(34)$ & $176(37)$ & 0.065 & $116(35)$ & $154(35)$ & 0.006 \\
\hline
\end{tabular}

Values are number (\%) or mean (standard deviation). All variables were preoperative or operative day variables. Lower education, high school graduate or less; pulmonary dysfunction, current smoker + lung disease + FEV1 $<60 \%$; vasopressors, phenylephrine, or norepinephrine; inotropes, dopamine, or dobutamine; fluid balance is (input [fluid + transfusion] - output [urine + blood + chest bottle]) on operative day. $C$, Crystalloid; $H$, hydroxyethyl starch; SMD, standardized mean difference; $B M I$, body mass index; $\mathrm{ASA}$, American Society of Anesthesiologists; $\mathrm{Hg}$, hemoglobin.

diabetes mellitus, hypertension, pulmonary dysfunction, cardiac disease, cerebral disease, liver disease, preoperative creatinine, preoperative albumin, preoperative hemoglobin, operation day vasopressors, operation day inotropes, operation day transfusion, operation day fluid balance, minimally invasive surgery, and thoracic epidural analgesia. PSM results are shown in Tables 3 and 4 with the PSM balance table in Figure 2. Standardized mean difference after matching was less than 0.1 in all variables.

There was a significant difference in the incidence of postoperative delirium between the $\mathrm{C}$ and $\mathrm{H}$ groups after PSM (number of delirium patients/number of matched population: $62 / 334[19 \%]$ and $109 / 439$ [25\%], $P=.04$; OR, 1.45 ; $98 \%$ CI, 1.02-2.06, $P=.037$ ). Multivariable analysis in the PS-matched $\mathrm{C}$ and $\mathrm{H}$ groups showed age, preoperative pulmonary dysfunction, transfusion, preoperative creatinine, and hydroxyethyl starch administration as risk factors for delirium (Table 5). The area under the receiver operating characteristics curve of this multivariable logistic regression model was 0.68 (95\% CI, 0.65-
0.72). $P$ value of Hosmer and Lemeshow goodness-of-fit was .63.

There was no significant difference in the incidence of postoperative delirium between the $\mathrm{C}$ and $\mathrm{A}$ groups after PSM (number of delirium patients/number of matched population: $31 / 140[22 \%]$ and 20/74 [27\%], $P=.48$; OR, 1.29; $98 \% \mathrm{CI}, 0.67-2.48 ; P=.44)$. Multivariable analysis in the PS-matched $\mathrm{C}$ and A groups showed age and preoperative albumin level as risk factors for delirium (Table 5). Albumin administration on operation day was not a risk factor (OR, $1.29 ; 95 \%$ CI, $0.66-2.50 ; P=.45)$. The area under the receiver operating characteristics curve of this multivariable logistic regression model was 0.74 (95\% CI, 0.68-0.80). $P$ value of Hosmer and Lemeshow goodness-of-fit was .53.

Postoperative complications and use of opioid and sedatives within POD4, which may contribute to early postoperative delirium, were compared among the 3 groups. Complications and use of opioids were not different among the 3 groups. Use of sedatives was higher in the A group compared with the other groups (Table 6). 
TABLE 4. Propensity score matching between crystalloid alone group and albumin group

\begin{tabular}{|c|c|c|c|c|c|c|}
\hline \multirow[b]{2}{*}{ Risk factors } & \multicolumn{3}{|c|}{ Before matching } & \multicolumn{3}{|c|}{ After matching } \\
\hline & $\overline{C(n=391)}$ & $A(n=78)$ & SMD & $\overline{C(n=140)}$ & $A(n=74)$ & SMD \\
\hline Male, $n(\%)$ & $348(89)$ & $73(94)$ & 0.163 & $131(93)$ & $69(93)$ & $<0.001$ \\
\hline Age, y & $63(9)$ & $63(9)$ & 0.008 & $63(9)$ & $63(10)$ & 0.004 \\
\hline BMI, $\mathrm{kg} /(\mathrm{m})^{2}$ & $23(3)$ & $22(3)$ & 0.073 & $22(3)$ & $22(4)$ & 0.013 \\
\hline ASA class III, $\mathrm{n}$ & $21(5)$ & $4(5)$ & 0.011 & $10(7)$ & $4(5)$ & 0.083 \\
\hline Lower education, $\mathrm{n}$ & $281(72)$ & $61(78)$ & 0.147 & $110(78)$ & $57(77)$ & 0.032 \\
\hline Heavy drinking, $\mathrm{n}$ & $105(27)$ & $29(37)$ & 0.223 & $49(35)$ & $25(34)$ & 0.028 \\
\hline Diabetes mellitus, $\mathrm{n}$ & $59(15)$ & $13(17)$ & 0.043 & $20(14)$ & $11(15)$ & 0.019 \\
\hline Hypertension, $\mathrm{n}$ & $156(40)$ & $26(33)$ & 0.137 & $45(32)$ & $25(34)$ & 0.029 \\
\hline Pulmonary dysfunction, $\mathrm{n}$ & $94(24)$ & $19(24)$ & 0.007 & $32(23)$ & $17(23)$ & $<0.001$ \\
\hline Cardiac disease, $\mathrm{n}$ & $23(6)$ & $4(5)$ & 0.033 & $10(7)$ & $4(5)$ & 0.057 \\
\hline Cerebral disease, $\mathrm{n}$ & $18(5)$ & $3(4)$ & 0.038 & $4(3)$ & $3(4)$ & 0.075 \\
\hline Liver disease, $\mathrm{n}$ & $14(4)$ & $5(6)$ & 0.130 & $9(6)$ & $4(5)$ & 0.029 \\
\hline $\begin{array}{l}\text { Preoperative creatinine, } \\
\mathrm{mg} / \mathrm{dL}\end{array}$ & $0.9(0.3)$ & $0.9(0.2)$ & 0.099 & $0.9(0.3)$ & $0.9(0.2)$ & 0.030 \\
\hline Preoperative albumin, $\mathrm{g} / \mathrm{dL}$ & $4.3(0.4)$ & $4.2(0.4)$ & 0.318 & $4.2(0.4)$ & $4.2(0.4)$ & 0.012 \\
\hline Preoperative $\mathrm{Hgb}, \mathrm{g} / \mathrm{dL}$ & $14(2)$ & $13(2)$ & 0.308 & $13(2)$ & $13(2)$ & 0.039 \\
\hline Operative time, $\min$ & $298(98)$ & $306(99)$ & 0.083 & $303(101)$ & $306(99)$ & 0.026 \\
\hline Inotrope, $\mathrm{n}$ & $89(23)$ & $21(27)$ & 0.096 & $39(28)$ & $20(27)$ & 0.015 \\
\hline Vasopressor, $\mathrm{n}$ & $196(50)$ & $53(68)$ & 0.368 & $91(65)$ & $49(66)$ & 0.028 \\
\hline Transfusion, $\mathrm{n}$ & $66(17)$ & $22(28)$ & 0.274 & $36(26)$ & $20(27)$ & 0.031 \\
\hline Fluid balance, $\mathrm{mL}$ & $323(470)$ & $544(488)$ & 0.461 & $506(521)$ & $503(455)$ & 0.007 \\
\hline Minimally invasive surgery, $\mathrm{n}$ & $84(22)$ & $6(8)$ & 0.398 & $12(9)$ & $6(8)$ & 0.024 \\
\hline Epidural, n & $134(34)$ & $37(47)$ & 0.270 & $64(46)$ & $35(47)$ & 0.027 \\
\hline
\end{tabular}

Values are number (\%) or mean (standard deviation). All variables were preoperative or operative day variables. Lower education, high school graduate or less; pulmonary dysfunction, current smoker + lung disease + FEV1 $<60 \%$; vasopressors, phenylephrine, or norepinephrine; inotropes, dopamine, or dobutamine; fluid balance is (input [fluid + transfusion] - output [urine + blood + chest bottle]) on operative day. $C$, Crystalloid; $A$, albumin; $S M D$, standardized mean difference; $B M I$, body mass index; $A S A$, American Society of Anesthesiologists; $\mathrm{Hg}$, hemoglobin.

ICU stay (median [interquartile]: 2 [2-2] days, 2 [2-2] days, 2 [2-2] days, $P=.586$ ) and hospital stay (median [interquartile]: 12 [12-13] days, 13 [12-13] days, 13 [13-14] days, $\mathrm{C}, \mathrm{H}$, and A groups, respectively, $P=.166$ ) and inhospital mortality $(\mathrm{n}=3,7$, and $0, \mathrm{C}, \mathrm{H}$, and A groups, respectively, $P=.912$ ) were not different among the 3 groups. However, patients who developed delirium showed longer ICU and hospital stay and higher mortality (ICU stay: $2.6 \pm 3.6$ days and $8.0 \pm 14.6$ days in the delirium $(-)$ and $(+), P<.001$; hospital stay: $15 \pm 10$ days and $24 \pm 30$ days in the delirium $(-)$ and $(+), P<.001$; inhospital mortality: $\mathrm{n}=1$ and 9 in the delirium (-) and $(+), P<.001)$.

\section{DISCUSSION}

In our study, the incidence of early postoperative delirium was $22.7 \%$. Administration of hydroxyethyl starch but not albumin was an independent risk factor of postoperative delirium within POD 4. Other risk factors were age, preoperative cerebrovascular disease, pulmonary dysfunction, and transfusion.
The risk factors found in our study are in accordance with previously reported risk factors in other surgeries. ${ }^{1,2,5}$ However, to our knowledge, this is the first study to show that the type of fluid has an influence on early postoperative delirium.

We hypothesized that colloid would reduce postoperative delirium. However, contrary to our hypothesis, hydroxyethyl starch, the most commonly used synthetic colloid, was related to an increased incidence of postoperative delirium. As a possible explanation, subclinical brain edema induced by hydroxyethyl starch is suggested. In the capillaries of the brain, endothelial cell membranes are tightly opposed by zona occludens tight junctions ${ }^{22}$ that interfere with almost all influx into the brain parenchyma. ${ }^{23}$ Therefore, hydroxyethyl starch administration does not produce any cerebrovascular effect under normal circumstances. However, surgical pain, ${ }^{24,25}$ a surge in blood pressure, ${ }^{24,26}$ or inflammation ${ }^{25,27,28}$ induces breaks within the endothelial cell junctions and increases transvascular fluid filtration. ${ }^{29,30}$ For example, substance P, a transmitter of nociception in the central nervous system, stimulates 
Crystalloid vs. Hydroxyethyl starch

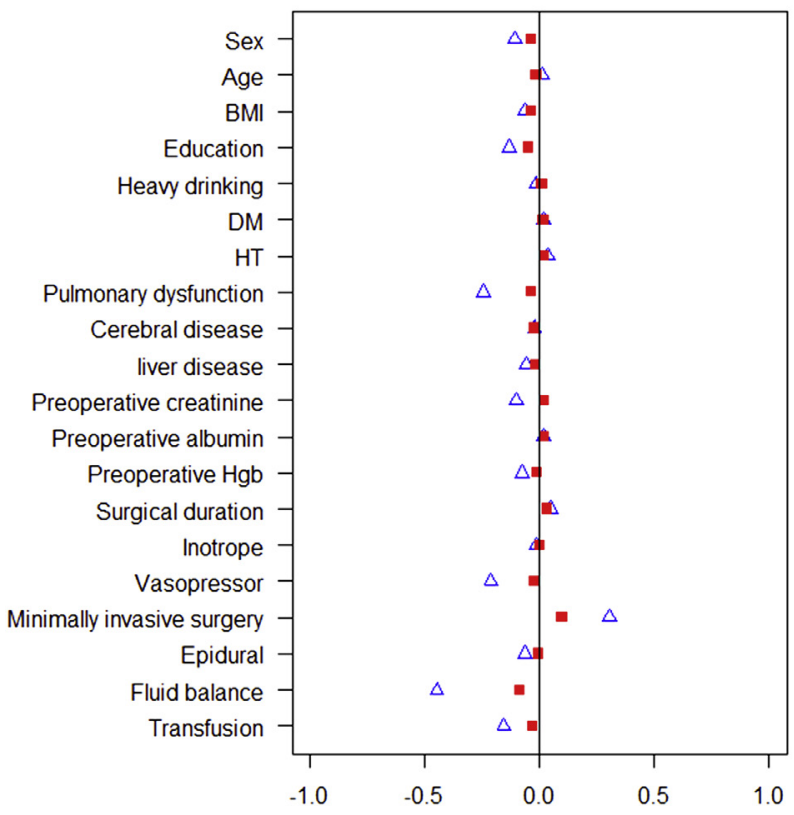

A

Standardized Difference

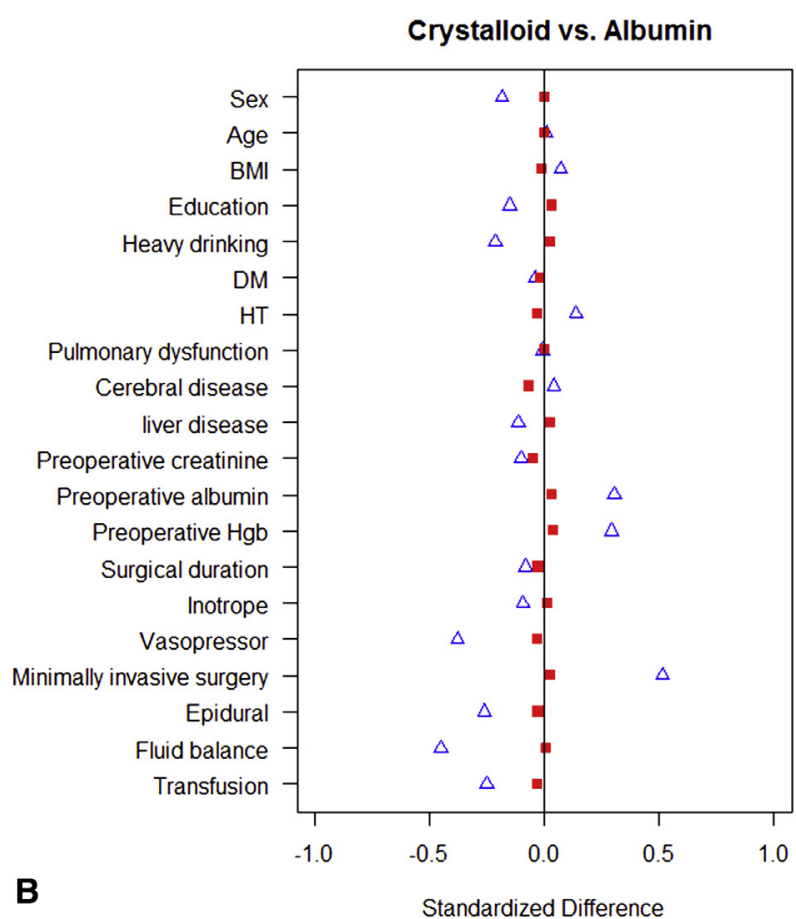

Standardized Difference

FIGURE 2. Covariance balance plots of standardized mean differences before (blue triangles) and after (red squares) PSM. A, Symbols to the left of 0 (negative values) indicate values more typical of the hydroxyethyl starch group, and symbols to the right (positive values) indicate values more typical of the crystalloid alone group. B, Symbols to the left of 0 (negative value) indicate values more typical of the albumin group, and symbols to the right (positive values) indicate values more typical of the crystalloid alone group. $B M I$, Body mass index; $D M$, diabetes mellitus; $H T$, hypertension; $H g b$, hemoglobin.

proinflammatory cytokines and increases permeability of the blood-brain barrier. ${ }^{25}$ Hypertension itself induces bloodbrain barrier breakdown. ${ }^{26}$ Esophagectomy, which accompanies extensive tissue injury, would be more likely to present these factors concurrently to a serious extent. ${ }^{31,32}$ Accordingly, a substantial change in blood-brain barrier permeability may occur after esophagectomy and allow the passage of fluids. ${ }^{33}$ In contrast to crystalloids that are excreted rapidly, the median serum half-life of hydroxyethyl starch is 38 hours $^{34}$ and volume expansion is seen for 24 to 48 hours until the starch is metabolized by amylase. . $^{35,36}$
Supporting this theory, hydroxyethyl starch infusion was related to a high mortality rate in patients with head injury. ${ }^{10}$ Bohner and colleagues ${ }^{37}$ found that infusion of more than $800 \mathrm{~mL}$ of colloid is an independent risk factor of postoperative delirium in vascular surgery.

In contrast, albumin administration was not related to postoperative delirium. There have been no studies to date on the association between albumin infusion and postoperative delirium. Maclullich and colleagues ${ }^{14}$ suggested that the cause of delirium is an unbalanced neuroinflammatory response. The production of proinflammatory cytokines

TABLE 5. Multivariable analysis for postoperative delirium in propensity-matched population

\begin{tabular}{|c|c|c|c|c|c|c|}
\hline \multirow[b]{2}{*}{ Risk factors } & \multicolumn{3}{|c|}{$\mathrm{C}$ and $\mathrm{H}$ groups combined } & \multicolumn{3}{|c|}{$\mathrm{C}$ and $\mathrm{A}$ groups combined } \\
\hline & OR & $95 \% \mathrm{CI}$ & $P$ & OR & $\mathbf{9 5} \% \mathrm{CI}$ & $P$ \\
\hline \multicolumn{7}{|l|}{ Fluids } \\
\hline Hydroxyethyl starch & 1.49 & $1.03-2.14$ & .033 & & & \\
\hline Albumin & & & & 1.29 & $0.66-2.50$ & .45 \\
\hline Age, per year & 1.10 & $1.02-1.07$ & .000 & 1.05 & $1.01-1.08$ & .020 \\
\hline Transfusion & 1.89 & $1.21-2.96$ & .005 & & & \\
\hline Pulmonary dysfunction & 1.72 & $1.17-2.51$ & .006 & & & \\
\hline Preoperative creatinine, per $\mathrm{mg} / \mathrm{dL}$ & 2.48 & $1.18-5.21$ & .017 & & & \\
\hline Preoperative albumin, per $\mathrm{g} / \mathrm{dL}$ & & & & 0.38 & $0.17-0.87$ & .020 \\
\hline
\end{tabular}


TABLE 6. Comparison of postoperative variables within postoperative day 4

\begin{tabular}{|c|c|c|c|c|}
\hline Risk factors & $C(n=393)$ & $H(n=509)$ & $\mathbf{A}(\mathbf{n}=78)$ & $\boldsymbol{P}$ \\
\hline Morphine, mg & $88 \pm 35$ & $88 \pm 37$ & $102 \pm 41$ & .006 \\
\hline Midazolam, mg & $2 \pm 3$ & $2 \pm 5$ & $2 \pm 3$ & .353 \\
\hline Complications, patients, $\mathrm{n}$ & $70(18)$ & $75(15)$ & $14(18)$ & .421 \\
\hline \multicolumn{5}{|l|}{ Pulmonary, event, $\mathrm{n}$} \\
\hline ALI/ARDS & 6 & 12 & 1 & \\
\hline Pneumonia & 5 & 11 & 3 & \\
\hline Atelectasis & 16 & 6 & 0 & \\
\hline Secretion retention & 3 & 1 & 2 & \\
\hline Prolonged air leak & 6 & 3 & 1 & \\
\hline Chylothorax & 1 & 1 & 0 & \\
\hline Pulmonary edema & 1 & 0 & 0 & \\
\hline Reintubation & 7 & 5 & 3 & \\
\hline Arrhythmia & 31 & 46 & 8 & \\
\hline Hepatobiliary & 2 & 1 & 1 & \\
\hline Graft & 0 & 2 & 1 & \\
\hline Wound infection & 1 & 0 & 0 & \\
\hline Bleeding & 2 & 3 & 0 & \\
\hline Emergency PCI & 2 & 0 & 0 & \\
\hline Brain infarction & 2 & 2 & 0 & \\
\hline AKI & 3 & 0 & 0 & \\
\hline Death & 0 & 0 & 0 & \\
\hline
\end{tabular}

Values are mean \pm standard deviation or number (\%). Morphine, $P=.027$ between crystalloid and albumin, $P=.006$ between hydroxyethyl starch and albumin, after Bonferroni correction. Cumulative dose of opioids until POD4 was transformed to the dose of morphine and cumulative dose of sedatives until POD4 was transformed to the dose of midazolam. Simple pleural effusion and trocha insertion was not included; pneumonia included aspiration pneumonia; atelectasis means complete lobar collapse and more; secretion retention only included severe retention that required bronchoscope toileting; prolonged air leak included emphysema and pneumothorax; graft included graft failure and anastomosis site leakage. $C$, Crystalloid; $H$, hydroxyethyl starch; $A$, albumin; $A L I$, acute lung injury; $A R D S$, acute respiratory distress syndrome; $P C I$, percutaneous coronary intervention; $A K I$, acute kidney injury.

induced by surgical trauma causes a series of inflammationassociated cognitive dysfunctions. ${ }^{13,14}$ Albumin is well known for its anti-inflammatory activity; albumin shows an inverse relationship with the concentration of proinflammatory cytokines such as interleukin- 6 and $8^{15}$ and inhibits tumor necrosis factor- $\alpha$ and interferon- $\gamma .{ }^{38}$ In contrast, the anti-inflammatory effect of hydroxyethyl starch remains controversial. ${ }^{39}$ In addition, the molecular weight of albumin is smaller than that of hydroxyethyl starches (66 vs 130$650 \mathrm{kDa}$ ), which may enable earlier removal of albumin from the circulation and tissues compared with hydroxyethyl starch. Therefore, the anti-inflammatory function and lower molecular weight of albumin may be responsible for the difference between the 2 types of colloid.

Transfusion, which was revealed as a risk factor in our study, has not received proper recognition as a provoker of postoperative delirium. However, a prospective observational study reported that transfusion is an independent risk

Postoperative delirium is common and related to increased hospital stay and morbidities in patients undergoing esophageal cancer surgery.

VIDEO 1. Hydroxyethyl starch infusion is related to early postoperative delirium in patients undergoing esophagectomy. Video available at: http://www.jtcvsonline.org/article/S0022-5223(17)32411-X/fulltext. factor of postoperative delirium in patients aged 65 years and older undergoing major noncardiac surgery. ${ }^{5}$ The suggested mechanism is also a systemic inflammatory reaction induced by transfusion. Every blood component, including iron and microparticles from destroyed red blood cells and substances produced during processing and storage, is known to provoke inflammation (Video 1). ${ }^{5,40}$

\section{Study Limitations}

The limitations of this study include the retrospective study design. The uncontrolled and unrecorded data inherent in the retrospective design might have influenced the results. Second, the selection of fluid type and amount was at the discretion of the attending physician with possible selection bias. Third, diagnosis of delirium in ward cannot be exact because it depends on the subscription of haloperidol without a record of CAM. The use of haloperidol may have been arbitrary and administered to patients with severe hyperactive delirium. Most patients are hypoactive rather than hyperactive during delirium episodes. Therefore, it is likely that delirium episodes were underdiagnosed in ward. Fourth, compared with the crystalloid and hydroxyethyl starch groups, the albumin group was small; therefore, it is possible that we have missed the possibility that both the albumin and 
hydroxyethyl starch groups have similar and higher occurrence of delirium than the crystalloid group. Finally, our results only represent the practice of a single center dedicated exclusively to cancer care and may not reflect practice at other institutions. High-volume randomized controlled trials are required to assess the full impact of fluid type and volume on postoperative delirium.

\section{CONCLUSIONS}

The incidence of early postoperative delirium in esophagectomy was $22.7 \%$. The risk factors of early postoperative delirium were age, preoperative cerebrovascular disease, pulmonary dysfunction, transfusion, and hydroxyethyl starch administration. In terms of postoperative delirium, albumin is more appropriate colloid than hydroxyethyl starch for replacement of blood loss or to achieve hemodynamic stability.

\section{Conflict of Interest Statement}

Authors have nothing to disclose with regard to commercial support.

The authors thank Kyunga Kim and Joong Hyun Ahn, biostatistician researchers in the Statistics and Data Center, Research Institute for Future Medicine, Samsung Medical Center, for statistical support.

\section{References}

1. Scholz AF, Oldroyd C, McCarthy K, Quinn TJ, Hewitt J. Systematic review and meta-analysis of risk factors for postoperative delirium among older patients undergoing gastrointestinal surgery. Br J Surg. 2016;103:e21-8.

2. Arenson BG, MacDonald LA, Grocott HP, Hiebert BM, Arora RC. Effect of intensive care unit environment on in-hospital delirium after cardiac surgery. $J$ Thorac Cardiovasc Surg. 2013;146:172-8.

3. Markar SR, Smith IA, Karthikesalingam A, Low DE. The clinical and economic costs of delirium after surgical resection for esophageal malignancy. Ann Surg. 2013;258:77-81.

4. Ely EW, Shintani A, Truman B, Speroff T, Gordon SM, Harrell FE Jr, et al. Delirium as a predictor of mortality in mechanically ventilated patients in the intensive care unit. JAMA. 2004;291:1753-62.

5. Behrends M, DePalma G, Sands L, Leung J. Association between intraoperative blood transfusions and early postoperative delirium in older adults. J Am Geriatr Soc. 2013;61:365-70.

6. Chau EH, Slinger P. Perioperative fluid management for pulmonary resection surgery and esophagectomy. Semin Cardiothorac Vasc Anesth. 2014;18:36-44.

7. Kita T, Mammoto T, Kishi Y. Fluid management and postoperative respiratory disturbances in patients with transthoracic esophagectomy for carcinoma. $J$ Clin Anesth. 2002;14:252-6.

8. Bundgaard-Nielsen M, Holte K, Secher NH, Kehlet H. Monitoring of perioperative fluid administration by individualized goal-directed therapy. Acta Anaesthesiol Scand. 2007;51:331-40.

9. Chappell D, Jacob M, Hofmann-Kiefer K, Conzen P, Rehm M. A rational approach to perioperative fluid management. Anesthesiology. 2008;109:723-40.

10. Lissauer ME, Chi A, Kramer ME, Scalea TM, Johnson SB. Association of 6\% hetastarch resuscitation with adverse outcomes in critically ill trauma patients. Am J Surg. 2011;202:53-8.

11. Guidet B, Martinet O, Boulain T, Philippart F, Poussel JF, Maizel J, et al. Assessment of hemodynamic efficacy and safety of $6 \%$ hydroxyethylstarch 130/0.4 vs. $0.9 \% \mathrm{NaCl}$ fluid replacement in patients with severe sepsis: the CRYSTMAS study. Crit Care. 2012;16:R94.

12. Annane D, Siami S, Jaber S, Martin C, Elatrous S, Declere AD, et al. Effects of fluid resuscitation with colloids vs crystalloids on mortality in critically ill patients presenting with hypovolemic shock: the CRISTAL randomized trial. JAMA. 2013;310:1809-17.

13. Dantzer R, Capuron L, Irwin MR, Miller AH, Ollat H, Perry VH, et al. Identification and treatment of symptoms associated with inflammation in medically ill patients. Psychoneuroendocrinology. 2008;33:18-29.

14. Maclullich AM, Ferguson KJ, Miller T, de Rooij SE, Cunningham C. Unravelling the pathophysiology of delirium: a focus on the role of aberrant stress responses. J Psychosom Res. 2008;65:229-38.

15. Zampieri FG, Kellum JA, Park M, Ranzani OT, Barbeiro HV, de Souza HP, et al. Relationship between acid-base status and inflammation in the critically ill. Crit Care. 2014;18:R154.

16. Tomita H, Ito U, Tone O, Masaoka H, Tominaga B. High colloid oncotic therapy for contusional brain edema. Acta Neurochir Suppl (Wien). 1994;60: $547-9$.

17. Jungner M, Grande PO, Mattiasson G, Bentzer P. Effects on brain edema of crystalloid and albumin fluid resuscitation after brain trauma and hemorrhage in the rat. Anesthesiology. 2010;112:1194-203.

18. Ely EW, Margolin R, Francis J, May L, Truman B, Dittus R, et al. Evaluation of delirium in critically ill patients: validation of the confusion Assessment Method for the Intensive Care Unit (CAM-ICU). Crit Care Med. 2001;90:1370-9.

19. Licker M, de Perrot M, Spiliopoulos A, Robert J, Diaper J, Chevalley C, et al. Risk factors for acute lung injury after thoracic surgery for lung cancer. Anesth Analg. 2003;97:1558-65.

20. Winger D, Nason K. Propensity-score analysis in thoracic surgery: when, why, and an introduction to how. J Thorac Cardiovasc Surg. 2016;151: 1484-7.

21. Austin P. Statistical criteria for selecting the optimal number of untreated subjects matched to each treated subject when using many-to-one matching on the propensity score. Am J Epidemiol. 2010;172:1092-7.

22. Sarin H. Physiologic upper limits of pore size of different blood capillary types and another perspective on the dual pore theory of microvascular permeability. $J$ Angiogenes Res. 2010;2:14.

23. Rubin LL, Staddon JM. The cell biology of the blood-brain barrier. Annu Rev Neurosci. 1999;22:11-28.

24. Oztas B, Akgul S, Arslan FB. Influence of surgical pain stress on the blood-brain barrier permeability in rats. Life Sci. 2004;74:1973-9.

25. Wolka AM, Huber JD, Davis TP. Pain and the blood-brain barrier: obstacles to drug delivery. Adv Drug Deliv Rev. 2003;55:987-1006.

26. Oztas B, Turkel N. Influence of an abrupt increase in blood pressure on the bloodbrain barrier permeability during acute hypertension and epileptic seizures. Pharmacol Res. 2001;44:209-12.

27. Huber JD, Witt KA, Hom S, Egleton RD, Mark KS, Davis TP. Inflammatory pain alters blood-brain barrier permeability and tight junctional protein expression. Am J Physiol Heart Circ Physiol. 2001;280:H1241-8.

28. Rochfort KD, Cummins PM. The blood-brain barrier endothelium: a target for pro-inflammatory cytokines. Biochem Soc Trans. 2015;43:702-6.

29. Lee WL, Slutsky AS. Sepsis and endothelial permeability. N Engl J Med. 2010; 363:689-91.

30. Clough G, Michel CC, Phillips ME. Inflammatory changes in permeability and ultrastructure of single vessels in the frog mesenteric microcirculation. J Physiol. 1988;395:99-114.

31. Yamada T, Hisanaga M, Nakajima Y, Kanehiro H, Watanabe A, Ohyama T, et al. Serum interleukin-6, interleukin-8, hepatocyte growth factor, and nitric oxide changes during thoracic surgery. World J Surg. 1998;22:783-90.

32. Wenk M, Schug SA. Perioperative pain management after thoracotomy. Curr Opin Anaesthesiol. 2011;24:8-12.

33. Drummond JC. Colloid osmotic pressure and the formation of posttraumatic cerebral edema. Anesthesiology. 2010;112:1079-81.

34. Wilkes NJ, Woolf RL, Powanda MC, Gan TJ, Machin SJ, Webb A, et al. Hydroxyethyl starch in balanced electrolyte solution (Hextend)-pharmacokinetic and pharmacodynamic profiles in healthy volunteers. Anesth Analg. 2002;94:538-44.

35. Hulse JD, Yacobi A. Hetastarch: an overview of the colloid and its metabolism. Drug Intell Clin Pharm. 1983;17:334-41.

36. Yacobi A, Stoll RG, Sum CY, Lai CM, Gupta SD, Hulse JD. Pharmacokinetics of hydroxyethyl starch in normal subjects. J Clin Pharmacol. 1982;22: 206-12.

37. Bohner H, Hummel TC, Habel U, Miller C, Reinbott S, Yang Q, et al. Predicting delirium after vascular surgery: a model based on pre- and intraoperative data. Ann Surg. 2003;238:149-56. 
38. Bar-Or D, Thomas GW, Bar-Or R, Rael LT, Scarborough K, Rao N, et al. Commercial human albumin preparations for clinical use are immunosuppressive in vitro. Crit Care Med. 2006;34:1707-12.

39. Lang JD Jr, Figueroa M, Chumley P, Aslan M, Hurt J, Tarpey MM, et al. Albumin and hydroxyethyl starch modulate oxidative inflammatory injury to vascular endothelium. Anesthesiology. 2004;100:51-8.
40. Garraud O, Hamzeh-Cognasse H, Laradi S, Pozzetto B, Cognasse F. Blood transfusion and inflammation as of yesterday, today and tomorrow. Transfus Clin Biol. $2015 ; 22: 168-77$.

Key Words: delirium, esophagectomy, hydroxyethyl starch

Readers who found these articles interesting may also like to read the following papers found in recent and future issues of our sister publications, Seminars in Thoracic and Cardiovascular Surgery and Operative Techniques in Thoracic and Cardiovascular Surgery!

\section{Thoracic: Esophagus}

ORIGINAL SUBMISSION: Thoracoscopic Surgery for a Congenital Bronchoesophageal Fistula with Pulmonary Sequestration in an Adult Woman Ichiro Sakanoue. Semin Thoracic Surg 2017: In press.

Editorial Commentary: Advanced Thoracoscopy: What is the Critical Information in Case Reports and How Do We Achieve the Next Level? Robert B. Cameron. Semin Thoracic Surg 2017: In press.

ORIGINAL SUBMISSION: Laparoscopic Repair of Large Hiatal Hernia Without the Need for Esophageal Lengthening With Low Morbidity and Rare Symptomatic Recurrence Farzaneh Banki. Semin Thoracic Surg 2017: In press.

ORIGINAL SUBMISSION: Black and White Esophagus: Rare Presentations of Severe Esophageal Ischemia Daniel B. Kim. Semin Thoracic Surg 2017: 256-259.

Editorial Commentary: Black Esophagus, White Esophagus, or Shades of Gray? Justin D. Blasberg. Semin Thoracic Surg 2017: 260261. 